\title{
Pyruvate: immunonutritional effects on neutrophil intracellular amino or alpha-keto acid profiles and reactive oxygen species production
}

\author{
D. Mathioudakis $\cdot$ J. Engel $\cdot$ I. D. Welters $\cdot$ M. G. Dehne $\cdot$ R. Matejec $\cdot$ \\ H. Harbach - M. Henrich - T. Schwandner - M. Fuchs - K. Weismüller • \\ G. J. Scheffer · Jörg Mühling
}

Received: 7 June 2010/Accepted: 23 August 2010/Published online: 14 September 2010

(C) The Author(s) 2010. This article is published with open access at Springerlink.com

\begin{abstract}
For the first time the immunonutritional role of pyruvate on neutrophils (PMN), free $\alpha$-keto and amino acid profiles, important reactive oxygen species (ROS) produced [superoxide anion $\left(\mathrm{O}_{2}{ }^{-}\right)$, hydrogen peroxide $\left(\mathrm{H}_{2} \mathrm{O}_{2}\right)$ ] as well as released myeloperoxidase (MPO) acitivity has been investigated. Exogenous pyruvate significantly increased PMN pyruvate, $\alpha$-ketoglutarate, asparagine, glutamine, aspartate, glutamate, arginine, citrulline, alanine, glycine and serine in a dose as well as duration of exposure dependent manner. Moreover, increases in $\mathrm{O}_{2}{ }^{-}$formation, $\mathrm{H}_{2} \mathrm{O}_{2}$-generation and MPO acitivity in parallel with intracellular pyruvate changes have also been detected.
\end{abstract}

D. Mathioudakis - J. Engel - M. G. Dehne - R. Matejec .

H. Harbach - M. Henrich

Clinics of Anaesthesiology, Intensive Care Medicine and Pain

Therapy, University Hospital Giessen and Marburg,

Justus-Liebig-University Giessen, Marburg,

Federal Republic of Germany

I. D. Welters · K. Weismüller

University Department of Anaesthesia, Royal Liverpool

University Hospital, Liverpool, UK

T. Schwandner

Department of General, Visceral, Thoracic, Transplantation and Pediatric Surgery, University Hospital Giessen and Marburg, Justus-Liebig-University Giessen, Marburg,

Federal Republic of Germany

M. Fuchs

Dr. Ing. Herbert Knauer GmbH, Berlin,

Federal Republic of Germany

G. J. Scheffer · J. Mühling ( $\square)$

Department of Anesthesiology, Pain, and Palliative Medicine,

Radboud University Medical Center, Huispost 630, route 630,

Postbus 9101, 6500 HB Nijmegen, The Netherlands

e-mail: j.muhling@anes.umcn.nl
Regarding the interesting findings presented here we believe, that pyruvate fulfils considerably the criteria for a potent immunonutritional molecule in the regulation of the PMN dynamic $\alpha$-keto and amino acid pools. Moreover it also plays an important role in parallel modulation of the granulocyte-dependent innate immune regulation. Although further research is necessary to clarify pyruvate's sole therapeutical role in critically ill patients' immunonutrition, the first scientific successes seem to be very promising.

Keywords Pyruvate $\cdot$ Neutrophil $\cdot$ Amino acids . $\alpha$-Keto acids - Immune function

\section{Introduction}

Increasing evidence suggests that the ketone pyruvic acid (the simplest $\alpha$-keto acid) may have immunonutritional significance in the modulation of PMN host defence mechanisms and granulocytic immunoregulation because of its relevant role in cellular energetics and metabolism (i.e. as an important source of respiratory cellular fuel or further metabolic precursors). Indeed, in all prokaryotic or eukaryotic cells its carboxylate anion (known as pyruvate) is certainly an important chemical compound in biochemistry and therefore it is no particular surprise that pyruvate not only can be produced by different pathways (i.e. via glycolysis in which one molecule of glucose breaks down into two molecules of pyruvate or reversible transamination reactions, etc.), but also unites several key metabolic processes (Agam and Gutman 1972; Curi et al. 1989, 1988; Fauth et al. 1993 and 1990; Frei et al. 1975; Fuchs et al. 1994; Homem de Bittencourt et al. 1993; Ing et al. 1997; Newsholme et al. 1987; Wu et al. 2005 and 2003). 
In eukaryotic cells, for example, pyruvate is converted into acetyl-CoA, releasing NADH and carbon dioxide in a process called pyruvate decarboxylation (Fauth et al. 1993 and 1990; Fink 2008, 2007a, b, 2004; Willems et al. 1978). This oxidative conversion into acetyl-CoA, which is the main input for a series of reactions named after Hans Adolf Krebs (awarded the 1953 Nobel Prize) is usually catalysed by the pyruvate dehydrogenase complex as part of aerobic respiration (Krebs 1940; 1938). Interestingly, the pyruvate decarboxylation process occurs inside the mitochondria after transport of the substrate, pyruvate from the cytosol (Aires et al. 2008; Brivet et al. 2003; Halestrap 1978; Vaartjes et al. 1979). Pyruvate decarboxylation is therefore an important link between the metabolic pathways of glycolysis, intracellular and mitochondrial amino acid turnover as well as the Krebs- so-called tri-carboxylic acid (TCA) cycle (Fink 2008, 2007a, b, 2004; Board and Newsholme 1996; Board et al. 1990; Brown et al. 2004). Once in the TCA cycle acetyl-CoA, which conveys the carbon atoms of pyruvate, can be oxidized to $\mathrm{CO}_{2}$ or serves as a precursor of numerous amino acids, synthetic metabolic intermediates as well as for macromolecular synthesis (Chang 1977; Das 2006a, b; Paul et al. 1987; Stjernholm et al. 1969). As quoted above, another important step in the formation or use of pyruvate is catalysed by rapid and reversible transamination reactions, for example catalysed via alanine transaminase, producing $\alpha$-ketoglutarate and alanine (Cicalese et al. 1996a, 1996b; Edlund and Halestrap 1988; Gardner and Leese 1988; Selvaraj and Sbarra 1966; Wiemer et al. 1995). For leukocytes this is of major importance, because $\alpha$-ketoglutarate, converted from pyruvate in particular, is responsible for key metabolic and synthetic roles which are essential in cellular viability (Curi et al. 1988; Gabbianelli et al. 2007; Mahiout et al. 1997; Miwa et al. 2000; Ramakrishnan et al. 1998; Zhou and Yu 1998) and can be very rapidly into a precursor of numerous amino acids, synthetic metabolic intermediates as well as macromolecular synthesis (Curi et al. 1989, 1988; Fuchs et al. 1994; Riedel et al. 1992; Serrano and Curi 1989; Venizelos and Hagenfeldt 1985). Interesting findings suggest indeed that $\alpha$-ketoglutarate, which is also one of the most important intracellular nitrogen transporters, is not only a key intermediate in the TCA cycle (coming after isocitrate and before succinyl CoA) but also can replenish the cycle in anaplerotic reactions. At this point, it is synthesised by transamination of glutamate or through action of glutamate dehydrogenase on glutamate (Cheng et al. 2007; Fink 2008, 2004; Frei et al. 1975; Willems et al. 1978).

Another important transamination product formed from pyruvate is alanine, which is most commonly produced by reductive amination (Board and Newsholme 1996 and Board et al. 1990; Curi et al. 1989, 1988). Because transamination reactions are readily reversible and pyruvate pervasive, alanine can be easily formed and thus, again, has close links to metabolic pathways such as glycolysis, gluconeogenesis and the TCA cycle (Fauth et al. 1990); Frei et al. 1975). Furthermore, pyruvate-through pyruvate carboxylase-can also be converted to oxaloacetate by an anaplerotic reaction. Interestingly, oxaloacetate is not only an important intermediate of the TCA cycle, but also the first designated substrate of the gluconeogenic pathways of all other cycle intermediates, glycerol or amino acids (Homem de Bittencourt et al. 1993; Newsholme et al. 1987; Stjernholm et al. 1969; Venizelos and Hagenfeldt 1985). Additionally, when oxygen is absent or in short supply, pyruvate can also be transformed to lactate by lactate dehydrogenase (LDH) (Gardner and Leese 1988; Serrano and Curi 1989; Willems et al. 1978). LDH is an ubiquitous enzyme and therefore present in a wide variety of cells, including neutrophils. It also catalyses the concomitant interconversion of NADH and NAD ${ }^{+}$.

The goals of this study are therefore to document the effects of pyruvate incubated in whole blood on neutrophilfree intracellular amino acid and $\alpha$-keto acid concentrations (regarding its role in PMN immunonutrition) as well as on the activities of released myeloperoxidase (MPO) and the formation of both superoxide anions $\left(\mathrm{O}_{2}{ }^{-}\right)$and hydrogen peroxide $\left(\mathrm{H}_{2} \mathrm{O}_{2}\right)$ (as markers of neutrophil function, and in order to show possible parallels with changes in neutrophil amino acid concentrations).

\section{Materials and methods}

The study was approved by the local ethics committee of the Justus Liebig University, Giessen, Germany. Ten men between 24 and 41 years $(31 \pm 6.3)$ with an average height of $179.8 \mathrm{~cm}$ (range 173-188) and weight of $82.6 \mathrm{~kg}$ (range 75-94) were selected. Those men with metabolic disease (e.g. diabetes, etc.), cardiopulmonary, neurological, allergic diseases or taking drugs were excluded. Whole blood samples (lithium-heparinate plastic tubes) were withdrawn between 08:00 and 09:00 (after 10 h of fasting) with consideration of circadian variations.

\section{Pyruvate}

1. To document any dose-dependent effects, whole blood samples were incubated with different pyruvate concentrations $(0,50,100,200$ or $500 \mu \mathrm{M}$ and $1 \mathrm{mM})$ for $120 \mathrm{~min}$. The selected pyruvate concentration corresponded to $0-, 1 / 2-, 1-, 2-, 5$ - and 10-fold the clinically achieved plasma concentrations (see Mühling et al. (2003) and Riedel et al. (1992) for physiological values). 
2. To examine whether there would be a critical duration of exposure needed to produce any significant effects, whole blood samples were incubated with pyruvate (1 $\mathrm{mM}$ ) for 10,60 or $120 \mathrm{~min}$.

Solutions of pyruvate were prepared and diluted in Hank's balanced salt solution (HBSS; Sigma, Deisenhofen, Germany) and the $\mathrm{pH}$ in the test solution was confirmed to be 7.4. One millilitre of whole blood was incubated with $25 \mu \mathrm{l}$ of test solution (final pyruvate concentrations were as described above) at $37^{\circ} \mathrm{C}$ using a vibrating water bath. Corresponding volumes of HBSS were added to the control tubes. Prior to processing further, all fractions were immediately cooled in an ice water bath at $4^{\circ} \mathrm{C}$ and $100 \mu \mathrm{g} / \mathrm{ml}$ phenyl methyl sulfonyl fluoride (PMSF), $10 \mu \mathrm{g} / \mathrm{ml}$ leupeptin, $10 \mu \mathrm{g} / \mathrm{ml}$ pepstatin, as well as $10 \mu \mathrm{g} / \mathrm{ml}$ antipain (all acquired from Sigma, USA) were added to each plastic heparin tube before the blood samples; these additions served to inhibit proteases.

Highly selective separation of PMN from whole blood

PMN cell fractionation and PMN cytolysis from whole blood after incubation with pyruvate were particularly interesting aspects of this study concerning the further analysis which followed [precise details of our PMNseparation technique have been described previously (Krumholz et al. 1995, 1993; Mühling et al. 2003, 1999). Only preparation procedures, which prevent further metabolic activity and thereby reflect metabolic state at the time of sampling are appropriate for: (1) allowing intragranulocyte free amino and $\alpha$-keto acid metabolism or immune functions to be analysed with a high degree of accuracy and precision, and (2) detecting small changes in metabolism. Thus, the goal must be to accomplish the fastest possible separation that retains complete activity, preserves cellular viability (without premature destruction of cellular integrity) and achieves a high degree of cell purity (Haslett et al. 1985; Rebecchi et al. 2000; Welters 2002). Moreover, continuous mechanical and chemical manipulation, changing temperatures, as well as sucrose containing density gradients, etc., may induce adverse effects on PMN due to a PMN activation such as spontaneous deformation, increased activities of extracellular released myeloperoxidase, elevated interleukin-8-transcription, increased PMN adhesion to glass surfaces, reduced chemotaxis or increased expression of complement receptors (Berger et al. 1984; Dooley et al. 1982; Welters 2002). Preliminary studies showed that despite these precautions, an activation of PMN could not always be avoided. In this study those cell suspensions identified, however, were removed from further analysis and evaluation (i.e. as indicated by a microscopic or macroscopic PMN aggregation). Our recent results, again, indicated that it was always necessary to check cell purity and viability to ensure precise and valid PML analysis. Moreover, these and former interesting findings were also an important reason for us to choose for all incubations a whole blood model (Krumholz et al. 1995, 1993; McCarthy et al. 1990; Welters 2002; Zhao et al. 2003). Another advantage is here, that many structures of an inflammatory matrix will remain during the incubation, since the immunological response of PMN mainly depends on the interactions with other blood or endothelial cells as well as on the cellular and immunological processes in the inflammatory area itself. Thus, important parameters remain stable during the incubation (i.e. continuous or physiological food and substrate supply for the PMN, maintained interactions with other blood cells, plasmatic inflammatory parameters, proteins, proteases or enzymes, etc.). For this reason there is an important advantage: the following findings in PMN are the results of nutrient interaction and biochemical communication of PMN with all structures located in whole blood and not only the results of a physiologically, biochemically and nutritionally environment-deprived single cell type. This offers a maximum proximity to the clinical question: do patients with serious diseases have a benefit from pyruvateenriched immunonutrition?

For the above reasons, we did not choose a sucrose containing density gradient (i.e. Ficoll ${ }^{\circledR}$ ) but Percoll ${ }^{\circledR}$ gradient method for granulocyte separation. Our procedure is a further development of the methods described by Eggleton et al. (1989) and Krumholz et al. (1995, 1993), which allowed very rapid and highly selective enrichment of PMLs from very small quantities of blood. Although we used $4 \mathrm{ml}$ of whole blood, $0.2 \mathrm{ml}$ was enough for the isolation of sufficient granulocytes for HPLC analysis. Cooling of the whole blood samples and of the gradients to $4^{\circ} \mathrm{C}$ did not have an effect on granulocyte quality (i.e. as was confirmed by light microscopy), and as described above, large numbers of cells could be separated with a high level of vitality, even from small quantities of whole blood. Cell yields were determined at the same time that vitality was measured. For duplicate determination, the percentage deviation in the numbers of cells amounted to less than 2\%. Separation of PMN was accomplished using a cooled $\left(4^{\circ} \mathrm{C}\right)$ Percoll $^{\circledR}$-gradient (Pharmacia, Uppsala, Sweden). Three $4 \mathrm{ml}$ portions $(\Sigma=12 \mathrm{ml})$ of cooled whole blood from each volunteer were overlaid onto previously prepared and pre-cooled $\left(4^{\circ} \mathrm{C}\right) 70 / 55 \%$ (in $0.9 \% \mathrm{NaCl}$ ) Percoll $^{\circledR}$ gradients before centrifugation at $350 \times g$ for $15 \mathrm{~min}$ at $4^{\circ} \mathrm{C}$ (Biofuge ${ }^{\circledR}$, Heraeus, Hanau, Germany). This separates the $\mathrm{PMN}$ as a small layer between the erythrocyte and monocyte layers. The PMN was carefully removed from the sample and suspended in $10 \mathrm{ml}$ cooled $\left(4^{\circ} \mathrm{C}\right)$ phosphate-buffered saline (PBS) stock buffer (diluted 
$1: 10$, v/v; $10 \times$ PBS stock buffer, without $\mathrm{Ca}^{2+} / \mathrm{Mg}^{2+}$, Gibco, Karlsruhe, Germany). After a second centrifugation step $\left(350 \times g\right.$ for $5 \mathrm{~min}$ at $\left.4^{\circ} \mathrm{C}\right)$, the PBS buffer was discarded and the erythrocytes remaining in the sample were hypotonically lysed using $2 \mathrm{ml}$ of cooled $\left(4^{\circ} \mathrm{C}\right)$ distilled water (Pharmacia, Uppsala, Sweden). After $20 \mathrm{~s}$ the PMN fraction was immediately brought back to isotonicity by the addition of $1 \mathrm{ml}$ of $2.7 \% \mathrm{NaCl}$ (Merck, Darmstadt, Germany) at $4{ }^{\circ} \mathrm{C}$ and resuspended by adding $10 \mathrm{ml}$ of diluted stock PBS buffer. After a third centrifugation step $\left(350 \times g\right.$ for $5 \mathrm{~min}$ at $\left.4{ }^{\circ} \mathrm{C}\right)$ the $\mathrm{PBS}$ buffer was discarded and the PMN fraction again resuspended (200 $\mu$ l PBS buffer). Subsequently, all PMN fractions were combined and two aliquots of resuspended sample were removed for microscopy (in this study the average purity of the separated cells was $97.6 \pm 0.8 \%$ and the average viability was $98.4 \pm 0.7 \%$ because samples with a PMN purity and vitality $\leq 95 \%$ were discarded). On average, the cell fractionation procedure lasted $35 \pm 6 \mathrm{~min}$. Immediately after preparation, the extracted PMN samples were frozen at $-80^{\circ} \mathrm{C}$ before lyophilisation (freeze dryer CIT- $2^{\circledR}$, Heraeus, Hanau, Germany). These conditions allowed for a PMN lysis, which was not chemically mediated and guaranteed longer analyte stability during extended storage of the sample. Samples prepared in this manner were stored at $-80^{\circ} \mathrm{C}$ until analysed within a period not exceeding 4 weeks. The purity, determined in duplicate in the first aliquot by dyeing with "Türk's Solution ${ }^{\circledR} "$ (Merck) and viability, determined in the second aliquot by exclusion of "Trypan Blue ${ }^{\circledR}$ " (Merck) was examined and verified by light microscopy (Zeiss, Oberkochen, Germany). Cell yields were determined at the same time that viability was measured; samples with a PMN purity and viability $<95 \%$ were discarded. In parallel, plasma samples $(100 \mu \mathrm{l})$ were separated, lyophilised and stored using known techniques. Overall, this method allows a very rapid and selective enrichment of neutrophils while preserving high cellular viability and integrity from very small quantities of whole blood.

\section{Chromatographic amino and $\alpha$-keto acid analysis}

Amino and $\alpha$-keto acids in PMN were quantified using previously described methods which fulfilled the strict criteria required for ultrasensitive, comprehensive amino acid and $\alpha$-keto acid analysis, specially developed and precisely validated in our institute for this purpose. Moreover, the coefficients of variations (for method reproducibility and reproducibilities of retention times) were also within normal ranges (for details see Mühling et al. 2003, 1999). PMN amino acid concentrations are given in $10^{-16}$ mol per neutrophil-cell; PMN $\alpha$-keto acid concentrations are given in $10^{-17} \mathrm{~mol}$ per neutrophil-cell.

Preparation of derivatization reagent

For the fluorescence labelling of the $\alpha$-keto acids, we used $o$-phenylenediamine (OPD, Sigma, Deisenhofen, Germany). Since oxidation of OPD influences the results in a negative way (the oxidised reagent causes variation in the fluorescence intensity) the brown powder must be re-crystallised prior to use. Although the amount of reactive OPD is less when using the oxidised form of the reagent, this recrystallisation procedure is necessary even when starting with the originally supplied substance. The $o$-phenylenediamine was dissolved in heptane at a temperature of $100-120^{\circ} \mathrm{C}$ (oil bath, Merck) and the heptane subsequently evaporated in a rotary evaporator (Merck). This procedure yielded a white powder after drying. With storage under $\mathrm{N}_{2}$ (Sigma, Deisenhofen, Germany) and at $4^{\circ} \mathrm{C}$ in a dark bottle, the dry substance is useable for several months. For each batch of analyses, the OPD reagent must be freshly prepared. For each sample, $5 \mathrm{mg}$ of OPD was dissolved in $5 \mathrm{ml}$ of $3 \mathrm{M}$ $\mathrm{HCl}(\sigma)$ and $10 \mu \mathrm{l}$ of 2-mercaptoethanol $(\sigma)$ was added to yield OPD-HCl-ME. This reagent solution was stable for several hours without loss in sensitivity (Fuchs et al. 1994).

Standard samples and precolumn derivatization procedure

Analytically pure $\alpha$-keto acids $(\sigma)$ were dissolved in distilled $\mathrm{H}_{2} \mathrm{O}$ (Merck) containing $4 \%$ human serum albumin (Merck), immediately lyophilised and stored at $-80^{\circ} \mathrm{C}$. The lyophilisates (PMN, plasma and standard samples) were solubilised in $250 \mu \mathrm{l}$ of pure methanol (Mallinckrodt Baker B.V., Deventer, Holland). The methanol also contained the $\alpha$-keto acid, $\alpha$-ketovalerate $(\mathrm{KV} ; \sigma)$ as an HPLC internal standard. $\mathrm{KV}$ is a non-physiological $\alpha$-keto acid. After a 3-min incubation and a 3-min centrifugation step ( $3000 \times g$, Rotixa/KS ${ }^{\circledR}$, Tuttlingen, Germany), $200 \mu$ of the extracts was dried under $\mathrm{N}_{2}\left(10 \mathrm{~min}, 20^{\circ} \mathrm{C}\right.$, Messer, Griesheim, Germany). The OPD-HCl-ME reagent $(5 \mathrm{ml})$ was then added, and the samples were incubated for $60 \mathrm{~min}$ at $80^{\circ} \mathrm{C}$. The derivatization was stopped after exactly $60 \mathrm{~min}$ by cooling for $15 \mathrm{~min}$ in ice water. Ethyl acetate $(2 \mathrm{ml}, \sigma$ ) was added to the samples and mixed for $7 \mathrm{~min}$ in a rotary mixer (Merck) to extract the $\alpha$-keto acids. After extraction, the top ethyl acetate layer was then transferred to a glass vial (2-CRV ${ }^{\circledR}$, Chromacoll, Trumbull, USA). This procedure was repeated twice for each sample. The combined ethyl acetate portions were dried under $\mathrm{N}_{2}$ (30 min), re-solubilised in $120 \mu \mathrm{l}$ of methanol and $50 \mu \mathrm{l}$ of this mixture was injected onto the HPLC column. 
Fluorescence high-performance liquid chromatography

The fluorescence high-performance liquid chromatography system (F-HPLC) consisted of a pump with a controller for gradient programming ( $600 \mathrm{E}^{\circledR}$, Waters, Milford, MA, USA) and a programmable autosampler (Triathlon ${ }^{\circledR}$, Spark, Netherlands) with a Rheodyne injection valve and a $100 \mu \mathrm{l}$ sample loop (AS $300^{\circledR}$, Sunchrom, Friedrichsdorf, Germany). A Nova-Pak ${ }^{\circledR}, 300 \times 3.9$ mm i.d., RP-C-18, $60 \AA, 4 \mu \mathrm{m}$ (Waters) analytical column was used for separation. Column temperatures were maintained at $35^{\circ} \mathrm{C}$ using a column oven (Knauer, Berlin, Germany). The column eluent was monitored using a fluorescence spectrophotometer (RF-530 ${ }^{\circledR}$, Shimadzu, Kyoto, Japan) at an excitation wavelength of $360 \mathrm{~nm}$ and an emission wavelength of $415 \mathrm{~nm}$. Data recording and evaluation was performed using computer integration software (EuroChrom $2000^{\circledR}$, Knauer, Berlin, Germany). The linear calibration curves were constructed based on area ratios of the standard $(\mathrm{St})$ to the sample (S) chromatograms ( $\left[\right.$ area $\mathbf{a}_{\text {keto acid }-\mathbf{S t}} /$ area $\left._{\text {internal standard-St }}\right] \times$ amount or concentration of keto acids injected $=$ calculation factor $(\mathrm{CF})$; $\left[\right.$ area $_{\text {keto acid-S }} /$ area $\left._{\text {internal standard }-\mathbf{s}}\right] \times \mathbf{C F}=$ final result). The flow rate was maintained at $1.0 \mathrm{ml} / \mathrm{min}$ throughout. For the gradient program and solvents, automatically degassed using a 3-channel degasser (Knauer, Berlin, Germany) see Mühling et al. (2003, 1999).

\section{Superoxide anion production}

Superoxide anion and hydrogen peroxide production as well as activity of released myeloperoxidase were determined photometrically using modifications of known methods validated in our institute for this purpose (for further details see Krumholz et al. 1995, 1993; Mühling et al. 2007, 2006, 2005, 2004, 2002). Superoxide anion production was measured by reduction of cytochrome C, $100 \mathrm{mg}$ of cytochrome C (type IV, Sigma, Deisenhofen, Germany) which was dissolved in $30 \mathrm{~mL}$ PBS $^{\circledR}$-glucose buffer. The solution was aliquoted and frozen at $-20^{\circ} \mathrm{C}$. Opsonized zymosan (Sigma, Deisenhofen, Germany) was used to stimulate PMN. It was produced by incubating $100 \mathrm{mg}$ zymosan with $6 \mathrm{~mL}$ pool serum for $30 \mathrm{~min}$ at $37^{\circ} \mathrm{C}$. After washing with saline and centrifugation at $350 \times \mathrm{g}(10 \mathrm{~min})$ opsonized zymosan was re-suspended in $10 \mathrm{~mL}$ PBS $^{\circledR}$-glucose buffer, aliquoted and frozen at $-20^{\circ} \mathrm{C}$. After incubation of whole blood with pyruvate at $37^{\circ} \mathrm{C}$, PMN was isolated as described above. Afterwards, the PMN was then isolated using a modification of our PMN-separation technique (as mentioned above). After stepwise $(15 \mathrm{~min}$ and $5 \mathrm{~min}$ ) centrifugation procedures $\left(350 \times g, 20^{\circ} \mathrm{C}\right)$ as well as careful lysis of a few erythrocytes contaminating the pellet, the pelleted PMN cells were re-suspended by adding diluted PBS $^{\circledR}$ (Gibco, Karlsruhe,
Germany) stock buffer. After $7 \mathrm{~mL}$ PBS $^{\circledR}$ stock buffer had been administered, the tube was centrifuged at $350 \times g$ for $5 \min \left(20^{\circ} \mathrm{C}\right)$. The supernatant was decanted. Samples with a PMN purity $<96 \%$ and those with more than $4 \%$ dead cells were discarded. The PMN concentration required in each case was adjusted by adding PBS containing $9.99 \mathrm{~g}$ glucose (Merck, Darmstadt, Germany). After PMN isolation, $500 \mu \mathrm{L}$ zymosan, $150 \mu \mathrm{L}$ pool serum, $250 \mu \mathrm{L}$ cytochrome $\mathrm{C}$ and $500 \mu \mathrm{L}$ isolated PMN suspension $\left(0.8 \times 10^{6} / \mathrm{mL}\right)$ and again pyruvate to be tested, were poured into a test tube. A preparation containing $500 \mu \mathrm{L}$ buffer instead of zymosan was used as a zero adjustment. After further incubation for $15 \mathrm{~min}$ at $37^{\circ} \mathrm{C}$ the reaction was stopped by putting the test tube into ice water. After centrifugation $(350 \times g ; 5 \mathrm{~min}$, $4^{\circ} \mathrm{C}$ ) extinction of the supernatant was measured photometrically $\left(546 \mathrm{~nm}\right.$; Digital photometer $6114 \mathrm{~S}^{\circledR}$; Eppendorf, Germany). The amount of superoxide anion produced was calculated and resulted from the extinction coefficient of cytochrome $\mathrm{C}$ according to the Lambert-Beer law. All control probes obtained for standard curves have been prepared, incubated and measured identically.

\section{Hydrogen peroxide production}

Hydrogen peroxide production was also determined photometrically. The method based on horseradish peroxidase catalysed by oxidation of phenol red by hydrogen peroxide. Phenol red (Sigma, Deisenhofen, Germany) and horseradish peroxidase (type II, Sigma, Deisenhofen, Germany) were added to PMN, which had been stimulated by opsonized zymosan. Phenol red was dissolved in double-distilled water $(10 \mathrm{~g} / \mathrm{L})$. Horseradish peroxidase was dissolved in $\mathrm{PBS}^{\circledR}{ }^{\circledR}$-glucose buffer $(5 \mathrm{~g} / \mathrm{L})$. After incubation of whole blood with pyruvate at $37^{\circ} \mathrm{C}$, PMN was isolated as described above. Isolated PMN was stimulated by opsonized zymosan (Sigma, Deisenhofen, Germany). The final test preparation consisted of $500 \mu \mathrm{L}$ zymosan, $125 \mu \mathrm{L}$ pool serum, $12.5 \mu \mathrm{L}$ horseradish peroxidase, $12.5 \mu \mathrm{L}$ phenol red, $12.5 \mu \mathrm{L}$ sodium azide $(200 \mathrm{mmol} / \mathrm{L} / \mathrm{l}$; Merck, Darmstadt, Germany), $500 \mu \mathrm{L}$ PMN suspension $\left(2 \times 10^{6}\right.$ PMN-cells $/ \mathrm{mL}$ ) and again pyruvate. After incubation for $15 \min \left(37^{\circ} \mathrm{C}\right)$, the test preparation was centrifuged for $5 \min \left(350 \times g ; 4^{\circ} \mathrm{C}\right)$. Subsequent to adding $25 \mu \mathrm{L}$ sodium hydroxide solution (1.0 normal, Merck, Darmstadt, Germany) the extinction was measured photometrically at $623 \mathrm{~nm}$. All control probes obtained for standard curves were prepared, incubated and measured identically.

Activity of released myeloperoxidase

Activity of released myeloperoxidase was also determined photometrically. $1 \mathrm{mmol} / \mathrm{L} \quad 2.2^{\prime}$-azino-di-(3-ethylbenzthiazoline) sulphonic acid (ABTS, Sigma, Deisenhofen, 
Germany) was dissolved in $0.1 \mathrm{~mol} / \mathrm{L}$ citrate buffer (Behring, Marburg, Germany; pH 7.4). After incubation of whole blood with pyruvate at $37^{\circ} \mathrm{C}, 100 \mu \mathrm{L}$ isolated PMN suspension $\left(2 \times 10^{6} / \mathrm{mL}\right)$ was incubated with $0.5 \mu \mathrm{g}$ cytochalasin B (Sigma, Deisenhofen, Germany) and again with pyruvate $\left(5 \mathrm{~min} ; 37^{\circ} \mathrm{C}\right)$. After adding $100 \mu \mathrm{L}$ opsonized zymosan and supplementing in order to keep the concentration constant, the preparation was incubated again for $10 \mathrm{~min}\left(37^{\circ} \mathrm{C}\right)$. Then $1 \mathrm{~mL}$ ATBS solution was added. After centrifuging $\left(700 \times g, 5 \mathrm{~min}, 20^{\circ} \mathrm{C}\right) 1 \mathrm{~mL}$ of supernatant was removed and mixed with $1 \mu \mathrm{L}$ hydroxide peroxide solution (30\%; Merck, Darmstadt, Germany) and extinction was measured photometrically $(405 \mathrm{~nm})$.

\section{Statistical analysis}

Statistical analysis and interpretation of the results were performed in close cooperation with colleagues from the Department of Medical Statistics, Justus Liebig University, Giessen, Germany. All tests were performed in duplicate. Thus our PMN amino acid results represent the mean of two estimations. After the results were demonstrated to be normally distributed (Pearson-Stephens test), statistical methods were performed including Bartlett's test to check homogeneity of variance $(p \leq 0.1)$. If the requirements were met, ANOVA analysis was conducted. If the requirements were not fulfilled, the Friedmann test was performed. Probability levels of $p \leq 0.05$ versus control were considered as significant. The data are given as arithmetic means \pm standard deviations (mean $\pm \mathrm{SD}$ ).

\section{Results}

The free intracellular amino and $\alpha$-keto acid concentrations, superoxide anion formation, hydrogen peroxide generation as well as activity of released myeloperoxidase obtained in the control cells were within normal physiological ranges (see Mühling et al. 2003, 1999) (Table 1). Intracellular pyruvate levels amounted on average to $6.36 \times 10^{-17} \mathrm{~mol}$ per neutrophil $(\mathrm{PMN})$ cell $(\approx 158 \mu \mathrm{mol} / \mathrm{L}$ PMN cell volume [NCV]; plasma: $117.6 \pm 42 \mu \mathrm{mol} / \mathrm{L})$. The intracellular $\alpha$-ketoglutarate content at almost $1.28 \times 10^{-17} \mathrm{~mol}$ per $\mathrm{PMN}$ cell $(\approx 32 \mu \mathrm{mol} / \mathrm{L} \mathrm{NCV}$; plasma: $7.6 \pm 2.1 \mu \mathrm{mol} / \mathrm{L})$ was approximately 3.7 times lower. The intragranulocytic amino acids glutamine, glutamate and alanine associated with pyruvate metabolism could also be exactly quantified: their average concentrations at $3.11 \times 10^{-16}$ mol per PMN cell (glutamine) $[\approx 773 \mu \mathrm{mol} / \mathrm{L} \mathrm{NCV}$; plasma: $546 \pm$ $191 \mu \mathrm{mol} / \mathrm{L}], 5.91 \times 10^{-16} \mathrm{~mol}$ per PMN cell (glutamate) [ $\approx 1.470 \mu \mathrm{mol} / \mathrm{L} \mathrm{NCV}$; plasma: $31 \pm 7 \mu \mathrm{mol} / \mathrm{L}])$ and $1.94 \times 10^{-16} \mathrm{~mol}$ per PMN cell (alanine) $[\approx 482 \mu \mathrm{mol} / \mathrm{L}$ $\mathrm{NCV}$; plasma: $354 \pm 83 \mu \mathrm{mol} / \mathrm{L}]$, respectively, were on
Table 1 Effects of pyruvate (PYR; $1 \mathrm{mM}$ ) incubated with whole blood for 10, 60 and $120 \mathrm{~min}$ on important free intracellular amino acids $\left(10^{-16}\right.$ Mol per PMN-cell; mean $\left.\pm \mathrm{SD} ; n=10\right)$, $\alpha$-ketoglutarate and pyruvate concentrations in PMN $\left(10^{-17}\right.$ Mol per PMN-cell; mean $\pm \mathrm{SD} ; n=10$ )as well as on PMN superoxide anion production $\left[\mathrm{O}_{2}{ }^{-} ; \mathrm{fmol} /(\mathrm{PMN} \mathrm{min})^{-1}\right]$, hydrogen peroxide formation $\left[\mathrm{H}_{2} \mathrm{O}_{2}\right.$; $\mathrm{fmol} /(\mathrm{PMN} \mathrm{min})^{-1}$ ] and myeloperoxidase activity [MPO; units/1 supernatant]; (mean $\pm \mathrm{SD} ; n=10$ )

\begin{tabular}{|c|c|c|c|c|c|c|}
\hline & \multicolumn{2}{|c|}{$10 \mathrm{~min}$} & \multicolumn{2}{|l|}{$60 \mathrm{~min}$} & \multicolumn{2}{|l|}{$120 \mathrm{~min}$} \\
\hline & Mean & SD & Mean & SD & Mean & SD \\
\hline \multicolumn{7}{|l|}{ Control } \\
\hline Asparagine & 0.39 & 0.10 & 0.41 & 0.09 & 0.37 & 0.09 \\
\hline Glutamine & 3.11 & 0.77 & 3.32 & 0.91 & 2.90 & 0.86 \\
\hline Aspartate & 2.65 & 0.73 & 2.80 & 0.61 & 2.56 & 0.57 \\
\hline Glutamate & 5.91 & 1.16 & 6.28 & 1.81 & 5.79 & 1.56 \\
\hline Ornithine & 0.46 & 0.08 & 0.49 & 0.08 & 0.45 & 0.09 \\
\hline Arginine & 0.35 & 0.07 & 0.37 & 0.07 & 0.34 & 0.08 \\
\hline Citrulline & 0.14 & 0.03 & 0.14 & 0.03 & 0.14 & 0.03 \\
\hline Serine & 2.30 & 0.44 & 2.22 & 0.53 & 2.07 & 0.45 \\
\hline Glycine & 2.47 & 0.56 & 2.35 & 0.49 & 2.29 & 0.58 \\
\hline Alanine & 1.94 & 0.46 & 1.86 & 0.46 & 1.81 & 0.59 \\
\hline$\alpha$-Ketoglutarate & 1.28 & 0.30 & 1.25 & 0.34 & 1.17 & 0.35 \\
\hline PYRUVATE & 6.36 & 1.84 & 6.14 & 1.93 & 5.92 & 1.56 \\
\hline $\mathrm{O}_{2}^{-}$ & 3.608 & 0.959 & 3.484 & 0.886 & 3.264 & 0.773 \\
\hline $\mathrm{H}_{2} \mathrm{O}_{2}$ & 1.279 & 0.316 & 1.263 & 0.365 & 1.198 & 0.304 \\
\hline MPO & 0.584 & 0.157 & 0.545 & 0.190 & 0.499 & 0.172 \\
\hline \multicolumn{7}{|l|}{ PYR (1 mM) } \\
\hline Asparagine & 0.40 & 0.11 & $0.53 *^{*}$ & 0.12 & $0.65^{* \#}$ & 0.17 \\
\hline Glutamine & 2.92 & 0.78 & $4.62 * \#$ & 1.27 & $5.54 * \#$ & 1.79 \\
\hline Aspartate & 2.87 & 0.80 & $4.27 *^{\#}$ & 1.32 & $5.18 * \#$ & 1.84 \\
\hline Glutamate & 6.90 & 1.45 & $11.66^{* \#}$ & 3.91 & $13.84 * \#$ & 4.32 \\
\hline Ornithine & 0.48 & 0.11 & 0.58 & 0.14 & $0.73^{* \#}$ & 0.24 \\
\hline Arginine & 0.36 & 0.10 & 0.42 & 0.11 & $0.48 * \#$ & 0.12 \\
\hline Citrulline & 0.13 & 0.03 & 0.14 & 0.04 & 0.16 & 0.05 \\
\hline Serine & 2.19 & 0.46 & 2.52 & 0.67 & $3.01 * \#$ & 0.66 \\
\hline Glycine & 2.22 & 0.44 & 2.54 & 0.59 & 3.41 *\# & 0.91 \\
\hline Alanine & 2.26 & 0.57 & $3.34 * \#$ & 0.98 & $5.05^{* \#}$ & 1.82 \\
\hline$\alpha$-ketoglutarate & 1.34 & 0.37 & $2.01 * \#$ & 0.57 & $2.78^{* \#}$ & 0.93 \\
\hline PYRUVATE & 7.23 & 2.29 & $12.07 * \#$ & 3.36 & $19.31 * \#$ & 7.54 \\
\hline $\mathrm{O}_{2}^{-}$ & 4.652 & 1.195 & $10.306^{* \#}$ & 3.051 & $17.091 *^{\#}$ & 6.560 \\
\hline $\mathrm{H}_{2} \mathrm{O}_{2}$ & 1.565 & 0.437 & $3.182 * \#$ & 0.846 & $4.992 * \#$ & 1.926 \\
\hline MPO & 0.672 & 0.211 & $1.208^{* \#}$ & 0.413 & $1.502 * \#$ & 0.738 \\
\hline
\end{tabular}

$* p \leq 0.05$ versus control values; \# $p \leq 0.05$ versus $10 \mathrm{~min}$

average more than an order of magnitude higher. Further interesting findings were also obtained for asparagine, aspartate, arginine, ornithine, serine and glycine. Their intracellular contents were on average $0.39 \times 10^{-16} \mathrm{~mol}$ (asparagine) $[\approx 97 \mu \mathrm{mol} / \mathrm{L} \mathrm{NCV}$; plasma: $61 \pm 19 \mu \mathrm{mol} /$ L], $2.65 \times 10^{-16} \mathrm{~mol}$ (aspartate) $[\approx 659 \mu \mathrm{mol} / \mathrm{L} \mathrm{NCV}$; plasma: $13 \pm 4 \mu \mathrm{mol} / \mathrm{L}]), 0.35 \times 10^{-16} \mathrm{~mol}$ (arginine) 
[ $\approx 87 \mu \mathrm{mol} / \mathrm{L} \mathrm{NCV;} \mathrm{plasma:} 79 \pm 20 \mu \mathrm{mol} / \mathrm{L}], 0.46 \times$ $10^{-16} \mathrm{~mol}$ (ornithine) $[\approx 114 \mu \mathrm{mol} / \mathrm{L} \mathrm{NCV}$; plasma: $42 \pm 20 \mu \mathrm{mol} / \mathrm{L}], 2.30 \times 10^{-16} \mathrm{~mol}($ serine $)[\approx 572 \mu \mathrm{mol} / \mathrm{L}$ $\mathrm{NCV}$; plasma: $118 \pm 33 \mu \mathrm{mol} / \mathrm{L}], \quad 2.47 \times 10^{-16} \mathrm{~mol}$ (glycine) $[\approx 614 \mu \mathrm{mol} / \mathrm{L} \mathrm{NCV}$; plasma: $251 \pm 53 \mu \mathrm{mol} / \mathrm{L}]$ ) and $0.14 \times 10^{-16} \mathrm{~mol}$ (citrulline) $[\approx 34.8 \mu \mathrm{mol} / \mathrm{L} \mathrm{NCV}$; plasma: $32 \pm 9 \mu \mathrm{mol} / \mathrm{L}]$ ) per $\mathrm{PMN}$ cell, respectively. However, the composition of these free amino acid and $\alpha$-keto acid pools does not appear to be arbitrary in any way. When comparing the intra versus the extracellular concentration gradient (i:e), the results painted a very different picture: for pyruvate (i:e: 1.3), glutamine (i:e: 1.4), alanine (i:e: 1.3), arginine (i:e: 1.1), serine (i:e: 4.8) and glycine (i:e: 2.4) not only high plasma but also high intracellular concentrations have been found, while $\alpha$-ketoglutarate (i:e: 4.2), glutamate (i:e: 47.4), aspartate (i:e: 50.6), asparagine (i:e: 1.6), ornithine (i:e: 2.7) with low plasma concentrations apparently accumulated within the neutrophils.

\section{Effects of pyruvate on free $\alpha$-keto acid pool in PMN}

$1 \mathrm{mM}$ pyruvate significantly increased pyruvate and $\alpha$-ketoglutarate profiles in a duration of exposure dependent manner (PMN incubation for $\geq 60 \mathrm{~min}$, Table 1). Following low pyruvate doses $(50 \mu \mathrm{M}$, PMN incubation for $120 \mathrm{~min}$ ), concentrations of free intracellular $\alpha$-keto acids remained unaffected. In the presence of higher pyruvate concentrations (PMN incubation for $120 \mathrm{~min}$ ) significant dose-dependent increases in PMN pyruvate and $\alpha$-ketoglutarate $(\geq 100 \mu \mathrm{M})$ were observed (Fig. 1). PMN

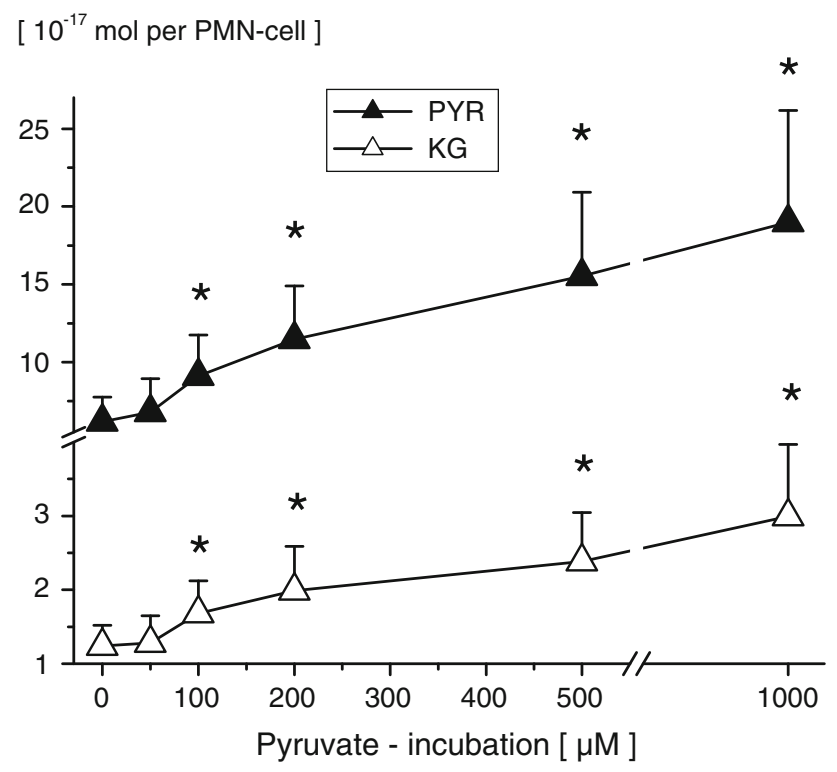

Fig. 1 Free intracellular pyruvate $(P Y R)$ and $\alpha$-ketoglutarate $(K G)$ concentrations in PMN-cells following pyruvate incubation $(0,50$, $100,200,500 \mu \mathrm{M}$ and $1 \mathrm{mM} ; 120 \mathrm{~min}$ ) of whole blood in vitro. PMN amino acid concentrations are given in $10^{-17} \mathrm{Mol}$ per PMN-cell (mean $\pm \mathrm{SD} ; n=10$ ). ${ }^{*} p \leq 0.05$ versus control values free $\alpha$-ketobutyrate, $\alpha$-ketoisovalerate, $\alpha$-ketoisocapronate, $p$-hydroxy-phenylpyruvate and $\alpha$-keto- $\beta$-methyl-valerate profiles remained unaffected.

Effects of pyruvate on free amino acid pool in PMN

Concentrations of free intracellular amino acids were unaffected by $50 \mu \mathrm{M}$ pyruvate (PMN incubation for $120 \mathrm{~min}$ ), respectively. Following higher pyruvate concentrations (PMN incubation for $120 \mathrm{~min}$ ), significant dose-dependent increases in PMN glutamate, asparagine, glutamine, aspartate, alanine ( $\geq 100 \mu \mathrm{M}$, Fig. 2), ornithine and arginine $(\geq 500 \mu \mathrm{M}$, Fig. 3$)$, as well as in serine and glycine ( $\geq 1 \mathrm{mM}$, Fig. 4) were observed. Moreover, $1 \mathrm{mM}$ pyruvate (PMN incubation for $\geq 60 \mathrm{~min}$ ) significantly increased PMN glutamate, glutamine, asparagine, aspartate, alanine, ornithine, arginine, glycine and serine in duration of exposure-dependent manner (Table 1). PMNfree citrulline, lysine, leucine, valine, methionine, taurine, hypotaurine, threonine, a-aminobutyrate, tyrosine, tryptophane, phenylalanine and histidine profiles remained unaffected.

Effects of pyruvate on oxidative response and myeloperoxidase activity

All PMN immune functions tested were unaffected up to $50 \mu \mathrm{M}$ pyruvate. In the presence of higher pyruvate

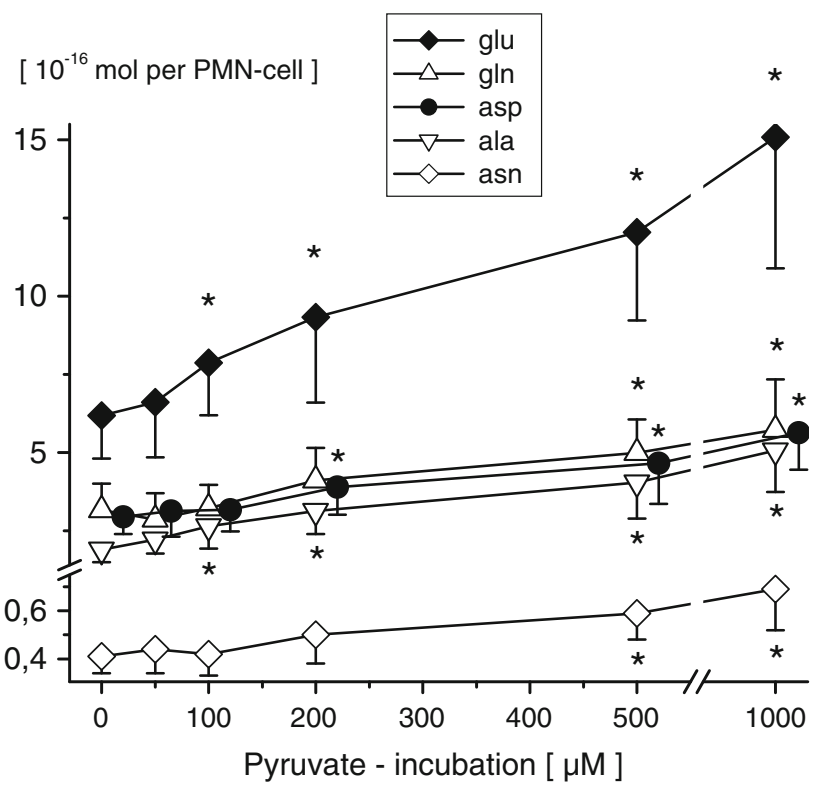

Fig. 2 Free intracellular glutamine $(g l n)$, glutamate $(g l u)$, asparagine (asn), aspartate (asp), and alanine (ala) concentrations in PMN-cells following pyruvate incubation $(0,50,100,200,500 \mu \mathrm{M}$ and $1 \mathrm{mM}$; $120 \mathrm{~min}$ ) of whole blood in vitro. PMN amino acid concentrations are given in $10^{-16} \mathrm{Mol}$ per PMN-cell (mean $\left.\pm \mathrm{SD} ; n=10\right)$. $*_{p} \leq 0.05$ versus control values 
[ $10^{-16} \mathrm{~mol}$ per PMN-cell) ]

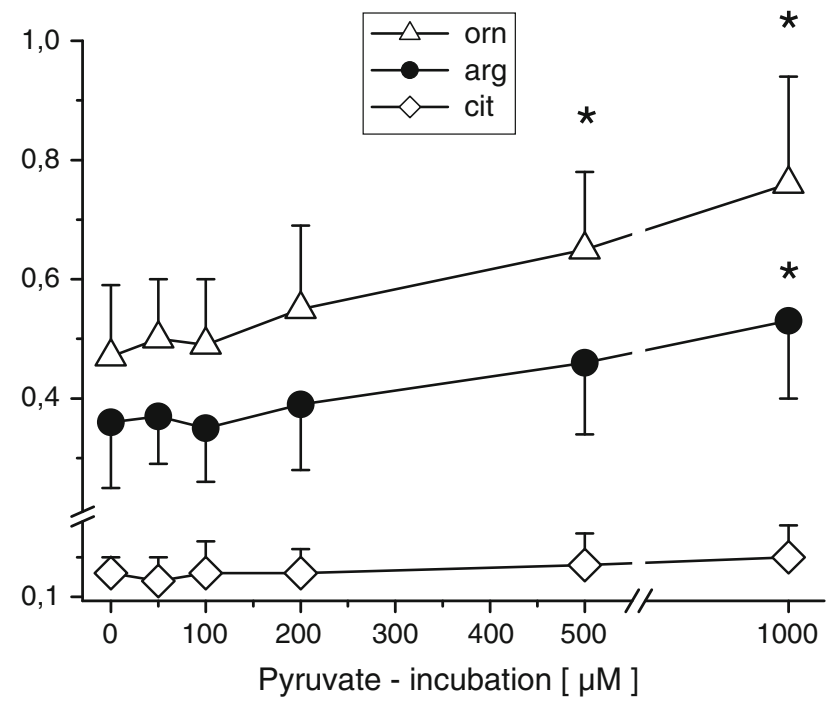

Fig. 3 Free intracellular ornithine (orn), arginine (arg) and citrulline (cit) concentrations in PMN-cells following pyruvate incubation $(0$, $50,100,200,500 \mu \mathrm{M}$ and $1 \mathrm{mM} ; 120 \mathrm{~min}$ ) of whole blood in vitro. PMN amino acid concentrations are given in $10^{-16} \mathrm{Mol}$ per PMN-cell (mean $\pm \mathrm{SD} ; n=10)$. $* p \leq 0.05$ versus control values

[ $10^{-16} \mathrm{~mol}$ per PMN-cell) ]

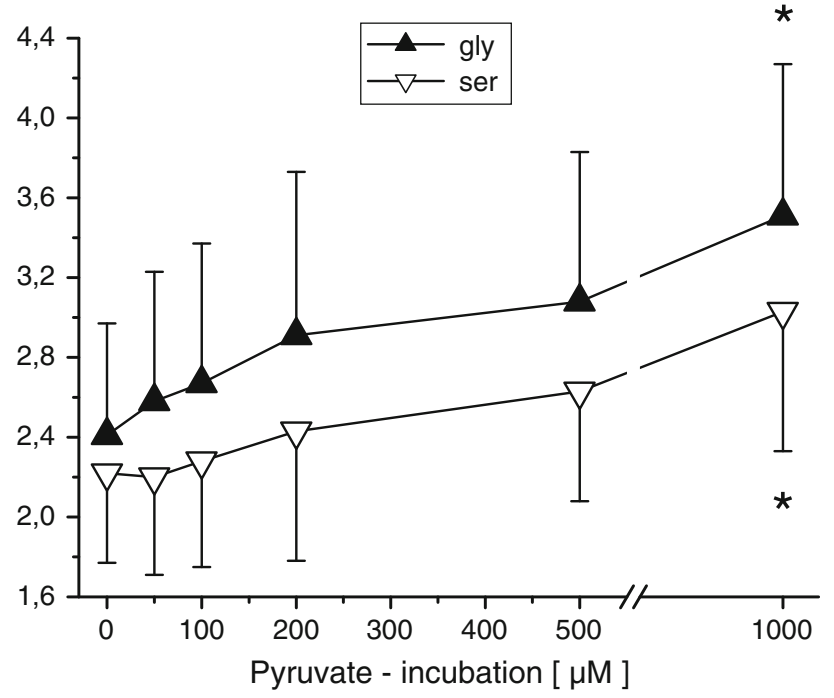

Fig. 4 Free intracellular glycine $(g l y)$ and serine (ser) concentrations in PMN-cells following pyruvate incubation $(0,50,100,200,500 \mu \mathrm{M}$ and $1 \mathrm{mM} ; 120 \mathrm{~min}$ ) of whole blood in vitro. PMN amino acid concentrations are given in $10^{-16}$ Mol per PMN-cell (mean $\pm \mathrm{SD}$; $n=10)$. ${ }^{*} p \leq 0.05$ versus control values

supplementation superoxide anion generation $(\geq 100 \mu \mathrm{M})$, hydrogen peroxide formation $(\geq 100 \mu \mathrm{M})$ and MPO activity $(\geq 200 \mu \mathrm{M})$ increased significantly in a dose-dependent manner (PMN incubation for 120 min, Fig. 5). Relevant changes in PMN immune functions tested mainly occurred with PMN incubation for 60 min or longer (Table 1).

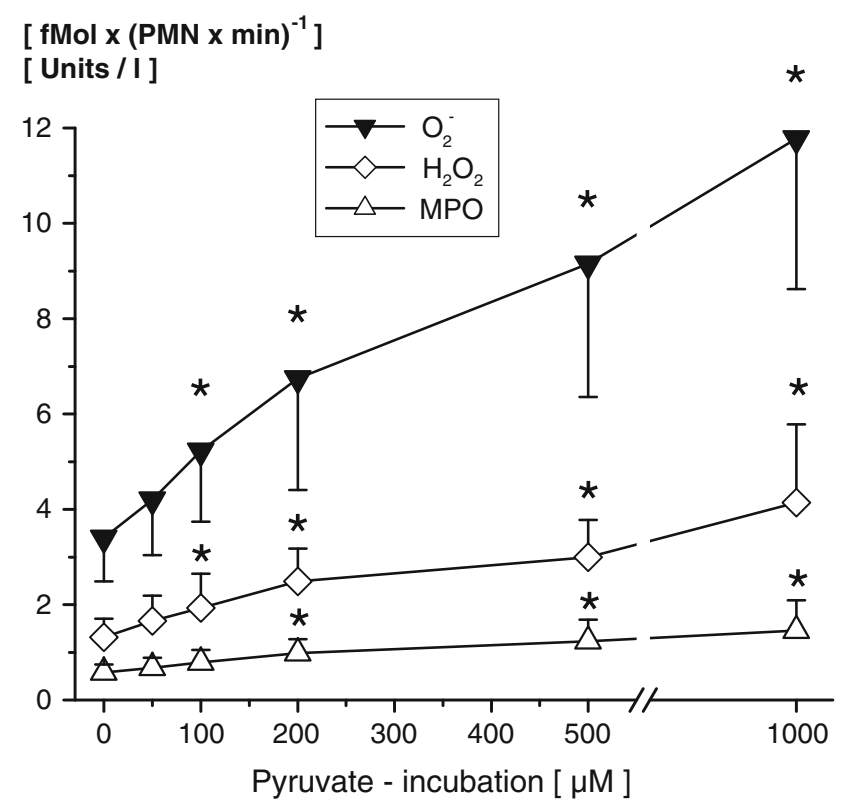

Fig. 5 Effects of different pyruvate concentrations (0, 50, 100, 200, $500 \mu \mathrm{M}$ and $1 \mathrm{mM}$; $120 \mathrm{~min}$ ) incubated with whole blood for $120 \mathrm{~min}$ on $\mathrm{PMN}$ superoxide anion production $\left[\mathrm{O}_{2}{ }^{-} ; \mathrm{fmol} /\right.$ $\left.(\mathrm{PMN} \mathrm{min})^{-1}\right]$, hydrogen peroxide formation $\left[\mathrm{H}_{2} \mathrm{O}_{2} ; \mathrm{fmol} /\right.$ $\left.(\mathrm{PMN} \mathrm{min})^{-1}\right]$ and myeloperoxidase activity [MPO; units/l supernatant]; (mean $\pm \mathrm{SD} ; n=10) . * p \leq 0.05$ versus control values

\section{Discussion}

For the first time the immunonutritional role of pyruvate on neutrophils (PMN), free $\alpha$-keto and amino acid profiles, important reactive oxygen species (ROS) produced [superoxide anion $\left(\mathrm{O}_{2}^{-}\right)$, hydrogen peroxide $\left(\mathrm{H}_{2} \mathrm{O}_{2}\right)$ ] as well as released myeloperoxidase (MPO) activity has been investigated. The results of our study presented here showed that exogenous pyruvate-incubated in whole blood-led to a significant increase in PMN intracellular pyruvate content, indicating a relevant transport across the plasmatic cell membrane. Indeed, essential to the roles of monocarboxylates such as lactate and pyruvate in cellular metabolism and metabolic communication between tissues is their rapid transport through different cell membranes, which for example is catalysed by a recently identified family of proton-linked monocarboxylate transporters (MCT's) or simply by diffusion (Brivet et al. 2003; Burckhardt and Burckhardt 2003; Kielducka et al. 1981; Kozlova et al. 1983; Lamers and Hulsmann 1975). MCT's are located at the plasma but also subcellular membranes (i.e. mitochondria) of human cells and classically transport metabolites across plasma membranes, directionally controlled by proton and metabolite concentrations and independently of energy input (Hume et al. 1978; Jolkver et al. 2009; Merezhinskaya and Fishbein 2009). Moreover, there is scientific evidence for the existence of a facilitated diffusion carrier, which specifically mediates the translocation 
of pyruvate. This transport system, which has been found in the plasma membrane of Trypanosoma brucei (bloodstream form), differs from other known monocarboxylate carriers present in the mitochondrial and/or plasma membrane of eukaryotic cells because of its high specificity for pyruvate and due to the fact that it does not transport L-lactate (Edlund and Halestrap 1988; Halestrap 1978; Poole et al. 1989; Wiemer et al. 1995). Interestingly, some important drugs may influence pyruvate transport mechanisms or even cellular pyruvate degradation. For example, Aires et al. (2008) reported the inhibition of the mitochondrial pyruvate uptake by the anticonvulsive drug valproic acid. But different antipsychotic drugs with clinically equivalent doses (i.e. chlorpromazine, thioridazine fluphenazine, thiothixene, etc.) are able to inhibit the pyruvate dehydrogenase complex (PDHC) to varying extents, too (Bakowski and Parekh 2007; Chen et al. 1998; Zhang et al. 2009).

Furthermore, although our study does not allow to infer whether the effects were direct (i.e. following uptake of important substrates by neutrophils produced from other blood cells) or metabolically induced changes brought about by pyruvate incubation of whole blood (i.e. following intracellular pyruvate conversion), however, referring to our findings we also note an relevant role of pyruvate as an important intragranulocyte substrate of various $\alpha$-keto and amino acid pathways (Agam and Gutman 1972; Mahiout et al. 1997; Miwa et al. 2000; Newsholme et al. 1987; Selvaraj and Sbarra 1966; Serrano and Curi 1989; Vaartjes et al. 1979; Willems et al. 1978). Since intracellular pyruvate increases the concentrations of $\alpha$-ketoglutarate as well as glutamine, glutamate, asparagine, aspartate, alanine, arginine, ornithine, glycine and serine were also significantly elevated in a dose as well as duration of exposure dependent manner. A more precise look at the constitution of PMN amino and $\alpha$-keto acid changes favour the hypothesis that increases in neutrophil free pyruvate concentrations are mainly followed by pyruvate conversion into important amino and $\alpha$-keto acid derivatives (Curi et al. 1989, 1988; Fuchs et al. 1994; Mühling et al. 2010, 2007, 2005, 2002). Indeed, our assumption that this metabolisation processes also occurs within PMN cells, may particularly be supported with regard to very similar immunonutritional findings induced by $\alpha$-ketoglutarate, alanyl-glutamine, ornithine or arginine in other leukocyte cells or even neutrophils. We therefore strongly suggest that pyruvate may act as preliminary stage substrate for subsequent intracellular metabolization. Interestingly, one of the most important cellular biochemical processes in which pyruvate is involved is its oxidative degradation, catalyzed by the pyruvate dehydrogenase complex (PDH) as part of aerobic respiration. The conversion-very far from equilibrium — of pyruvate to form
acetyl-CoA-accessorily releasing $\mathrm{NADH}$ and $\mathrm{CO}_{2}$ via decarboxylation is known as an important link reaction between the metabolic pathways of glycolysis and of course the citric acid cycle. There are either used as a substrate for oxidative phosphorylation, therefore serving as a respiratory fuel source or as a precursor of many synthetic intermediates and metabolic pathways (i.e. urea cycle [i.e. in the form of aspartate produced from oxalacetate] fatty acid, isoprenoid biosynthesis, etc.) (Agam and Gutman 1972; Board and Newsholme 1996, 1990; Brown et al. 2004; Newsholme et al. 1987; Stjernholm et al. 1969; Witko-Sarsat et al. 2000). Indeed, an absence of this enzyme complex has serious implications for the affected patients. For example, malfunction of the citric acid cycle due to PDH deficiency deprives the body of energy and leads to an abnormal buildup of lactate resulting in lactic acidosis in newborns and often presents with clinical signs like severe lethargy, poor feeding, tachypnea or cases of death (Curi et al. 1989 and 1988; Gardner and Leese 1988; Paul et al. 1987; Su et al. 2007; Venizelos and Hagenfeldt 1985). But for neutrophils, especially, the reversible transamination of pyruvate by the alanine aminotransferase (also known as glutamic pyruvic transaminase, GPT), also seems to be of further importance concerning their physiological tasks in whole body immune defense. In this case amino groups are transferred from glutamate to pyruvate producing alanine and $\alpha$-ketoglutarate which themselves in turn can directly be shunted into the tricarboxylic acid cycle and oxidatively decarboxylated to succinyl-CoA by the $\alpha$-ketoglutarate dehydrogenase complex (Fink 2004; Frei et al. 1975; Taylor et al. 2005; Willems et al. 1978). Furthermore, pyruvate may also be catalysed by an irreversible anaplerotic carboxylation (metabolized by pyruvate carboxylase), which provides oxalacetate precursors for the citric acid cycle but also-after conversion into phosphonenolpyruvate-for gluconeogenesis. Evidence for this exists as key enzymes for gluconeogenesis such as fructose-1,6-bisphosphatase had also been found in leukocytes (Agam and Gutman 1972; Fauth et al. 1993, 1990; Fink 2008 and 2004; Frei et al. 1975; Mackenzie and Lever 2007; Stjernhome et al. 1969). Moreover, pyruvate may also be a starting point for the "de novo synthesis" of alanine, serine and glycine as well as glucose. Enzymes required for this, especially NADPH-forming metabolic pathways, are certainly present in PMN cells as others have shown (Agam and Gutman 1972; Curi et al. 1989 and 1988; Fink 2008; Frei et al. 1975; Fuchs et al. 1994; Engel et al. 2009a, b; Mühling et al. 2010 and 2005; Newsholme et al. 1987; Serrano and Curi 1989). Concerning to the present but also former findings we therefore strongly believe, that the indirect availability of pyruvate in the form of glutamate, glutamine, $\alpha$-ketoglutarate, alanine, asparagine, aspartate, arginine, ornithine, serine or glycine 
may emphasise the fundamental importance of this molecule in restoring pathophysiological depleted amino and $\alpha$-keto acid pools (Mühling et al. 2001). Thus indirect regulation of arginine, ornithine or aspartate (i.e. via oxalacetate) metabolism (for example used as a substrate for the enzymes of the urea cycle or formation of phosphoserine and serine), the synthesis of $\bullet \mathrm{NO}$ required for PMN activation and ultimately the formation of glutamine, glutamate or $\alpha$-ketoglutarate metabolism (i.e. used for glutathione, proline, purine and pyrimidine synthesis, export of glutamate in exchange for import of cystine and following conversion to cysteine, synthesis of glucosamines or $\mathrm{NAD}+$, etc.) can all be modulated by pyruvateenriched immunonutrition in PMN (Agam and Gutman 1972; Curi et al. 1989, 1988; Fink 2008; Frei et al. 1975; Fuchs et al. 1994; Engel et al. 2009a, b; Mühling et al. 2010, 2005; Newsholme et al. 1987; Serrano and Curi 1989; Wu et al. 2005, 2003).

Nevertheless, the conversion of pyruvate does not just supply important precursors for the above-mentioned metabolic pathways, since it also provides energy-rich molecules such as nicotinamide adenine dinucleotide phosphate (NADPH) or guanosine-5' $5^{\prime}$-triphosphate (GTP). For example NADPH can not only arise from the conversion of pyruvate by pyruvate dehydrogenase, but also from the catalytic activities of the TCA cycle enzymes isocitrate, $\alpha$-ketoglutarate and malate dehydrogenase (Board et al. 1990; Brown et al. 2004; Chang et al. 1977; Mühling et al. 2010). Moreover, succinyl-CoA synthetase catalyzes another important step in the TCA cycle which involves the substrate-level phosphorylation of guanosine-5'-diphosphate to GTP, which acts as a important source of energy or as an activator of substrates in metabolic reactions (i.e. protein synthesis), like that of ATP, but more specific. Indeed, Hyslop et al. (1984) found that neutrophil homogenates contained a high affinity guanosine triphosphatase (GTPase) activity during chemotactic peptide stimulation in neutrophils. Furthermore, Woodman et al. (1988) described a relevant role for de novo protein synthesis in maintaining or augmentation of the chemotactic peptide-induced respiratory burst in neutrophils, manufacturing $\mathrm{O}_{2}{ }^{-}$. However, a closer look to granulocytic immune functions shows, that not only GTPase but also NADPHoxidase (NADPH-O) in particular, which can be found in the plasma membrane as well as in the membrane of phagosomes, plays a pivotal role in human immune regulation (Kang et al. 2002; Klein et al. 1990; Kobayashi et al. 2001). The complex is normally latent in neutrophils and is activated to assemble in the membranes during respiratory burst (Mühling et al. 2010, 2006, 2005, 2004, 2002). It primarily generates superoxide, a highly reactive free radical, by transferring electrons from NADPH inside the cell across the membrane and coupling these to molecular oxygen. In phagosomes or outside the cell, superoxide can spontaneously form hydrogen peroxide that will undergo further reactions to generate reactive oxygen species (ROS) (Newsholme et al. 1987; Wu et al. 2005, 2003; Zhou and Yu 1998). Superoxide is capable of killing bacteria and fungi by mechanisms that are not yet fully understood. It also may inactivate critical metabolic enzymes, initiate lipid peroxidation and liberate redox active iron, which allows the generation of indiscriminate oxidants such as the hydroxyl radical. Superoxide probably kills bacteria directly as the virulence of many pathogens is dramatically attenuated when their superoxide dismutase (SOD) genes are deleted (Engel et al. 2009a, b; Mühling et al. 2010, 2006, 2005, 2004, 2002; Wu et al. 2005, 2003). Therefore, superoxide is one of the main reactive oxygen species in neutrophils and as such, SOD plays a key antioxidant role. However, downstream products of superoxide also include hydrogen peroxide $\left(\mathrm{H}_{2} \mathrm{O}_{2}\right)$ and hypochlorous acid. In activated neutrophils during the respiratory burst, $\mathrm{HOCl}$ is produced by myeloperoxidase-mediated (MPO) peroxidation of chloride ions from $\mathrm{H}_{2} \mathrm{O}_{2}$. Indeed, a number of authors described that $\mathrm{HOCl}$ contributes to the destruction of bacteria by inhibition of important biochemical pathways [i.e. glucose oxidation (Knox et al. 1948)] or reacting with a wide variety of their biomolecules including depletion of adenine nucleotides (i.e. ATP hydrolysis), DNA and RNA (i.e. inhibition of replication) fatty acid groups (i.e. lipid hydrolysis which affect membrane permeability), cholesterol (forming toxic chlorhydrins) as well as post-translational modifications to proteins (i.e. protein unfolding and aggregation) (i.e. Cicalese et al. 1996a, 1996b; Dahlgren and Karlsson 1999; Ing et al. 1997, Huang et al. 2009; Wu et al. 2005, 2003). But regarding the "positive" or "desired" bacteriocidal nature of chlorine solutions induced by $\mathrm{HOCl}$ one should bear in mind that the diapedesis of immunonutritionally (i.e. following pyruvate) improved neutrophils in inflammatorily damaged extravascular matrices may also paradoxically wreak serious additional granulocyte-mediated injury to all cells or tissue structures with the potential risks of aggravating the course of the disease accidentally. Interestingly, recent findings showed that pyruvate may also have some antioxidant and anti-inflammatory actions as an effective scavenger of highly reactive oxygen species, for example produced by neutrophils (Engel et al. 2009a, 2009b; Matés et al. 2008; Mühling et al. 2010, 2006, 2005, 2004, 2002). Overall, referring to our results as well as regarding the beneficial immunonutritional effects found by others, it seems clear that pyruvate fulfills the criteria for a potent molecule in the regulation of the dynamic $\alpha$-keto and amino acid pools as well as in modulation of PMN host defense mechanisms and immunoregulation. Unfortunately, any further clarification of pyruvate's sole role of 
in vivo therapeutic immunonutritional properties may be associated with important galenical problems, mainly due to its instability in aqueous solutions. For this reason, current results which investigated ethyl pyruvate (EP), a simple aliphatic ester derived from pyruvate, seems very promising (Fink 2004; Zingarelli 2004). EP has shown to be safe at clinically relevant doses treatment with EP has been shown to improve survival and/or ameliorating organ dysfunction in a wide variety of clinical models of criticall illnesses as well as it has beneficial effects concerning disturbed cellular function in vitro (Cai et al. 2009; Cheng et al. 2007; Fink 2007a, b; Genovese et al. 2009; Lee et al. 2008; Tsung et al. 2005, Wang et al. 2009; Yang et al. 2009; Zhang et al. 2009). For example, EP has demonstrated anti-inflammatory actions, improved bacterial translocation or hyperpermeability due to endotoxinemia and may also has benefit in models of sepsis and septic shock by inhibiting tumor necrosis factor-alpha production and interleukin-6 mRNA expression in several tissues, or through a reduction of the enzyme activities of cyclooxygenase-2 or inducible nitric oxide synthase (Dave et al. 2009; Deng et al. 2009; Di et al. 2009; Hollenbach et al. 2008; Liang et al. 2009; Su et al. 2007; Taylor et al. 2005; van Zoelen et al. 2006). But the beneficial anti-inflammatory effects may also be due to modifications in the circulating levels of high mobility group box-1 and NF-kappaB signalling pathways (Fink 2008; Han et al. 2005; Matsumoto et al. 1991; Johansson et al. 2008; Su et al. 2008; Varma et al. 2006).

Although further research is necessary to clarify pyruvate's sole therapeutical role (for example given as EP) in critically ill patients immunonutrition, the first scientific successes seem to be very promising.

Conflict of interest The authors have no relationship, financial or otherwise, with individuals or organizations that could influence the author's work inappropriately, and a conflict of interest does not exist.

Open Access This article is distributed under the terms of the Creative Commons Attribution Noncommercial License which permits any noncommercial use, distribution, and reproduction in any medium, provided the original author(s) and source are credited.

\section{References}

Agam G, Gutman A (1972) Synthesis of glycogen in leucocytes from various precursors. Rev Eur Etud Clin Biol 17:650-656

Aires CC, Soveral G, Luis PB et al (2008) Pyruvate uptake is inhibited by valproic acid and metabolites in mitochondrial membranes. FEBS Lett 582:3359-3366

Bakowski D, Parekh AB (2007) Regulation of store-operated calcium channels by the intermediary metabolite pyruvic acid. Curr Biol 17:1076-1081

Berger M, O'Shea J, Cross AS, Folks TM, Chused TM, Brown EJ (1984) Human neutrophils increase expression of C3bi as well as C3b receptors upon activation. J Clin Invest 74:1566-1571
Board M, Newsholme E (1996) Hydroxycitrate causes altered pyruvate metabolism by tumorigenic cells. Biochem Mol Biol Int 40:1047-1056

Board M, Humm S, Newsholme EA (1990) Maximum activities of key enzymes of glycolysis, glutaminolysis, pentose phosphate pathway and tricarboxylic acid cycle in normal, neoplastic and suppressed cells. Biochem J 265:503-509

Brivet M, Garcia-Cazorla A, Lyonnet S et al (2003) Impaired mitochondrial pyruvate importation in a patient and a fetus at risk. Mol Genet Metab 78:186-192

Brown AC, Macrae HS, Turner NS (2004) Tricarboxylic-acid-cycle intermediates and cycle endurance capacity. Int J Sport Nutr Exerc Metab 14:720-729

Burckhardt BC, Burckhardt G (2003) Transport of organic anions across the basolateral membrane of proximal tubule cells. Rev Physiol Biochem Pharmacol 146:95-158

Cai B, Brunner M, Wang H et al (2009) Ethyl pyruvate improves survival in awake hemorrhage. J Mol Med 87:423-433

Chang YH (1977) Studies on phagocytosis-III. Tricarboxylic acid cycle and the cytochrome system as energy sources for phagocytosis in rabbit peritoneal exudate polymorphonuclear leukocytes. Biochem Pharmacol 26:1489-1493

Chen XZ, Shayakul C, Berger UV et al (1998) Characterization of a rat Na+-dicarboxylate cotransporter. J Biol Chem 273:20972-20981

Cheng BQ, Liu CT, Li WJ et al (2007) Ethyl pyruvate improves survival and ameliorates distant organ injury in rats with severe acute pancreatitis. Pancreas 35:256-261

Cicalese L, Lee K, Schraut W et al (1996a) Pyruvate prevents ischemia-reperfusion mucosal injury of rat small intestine. Am J Surg 171:97-100

Cicalese L, Rastellini C, Rao AS et al (1996b) Pyruvate prevents mucosal reperfusion injury, oxygen free-radical production, and neutrophil infiltration after rat small bowel preservation and transplantation. Transplant Proc 28:2611-2615

Curi R, Newsholme P, Newsholme EA (1988) Metabolism of pyruvate by isolated rat mesenteric lymphocytes, lymphocyte mitochondria and isolated mouse macrophages. Biochem J 250:383-388

Curi R, Williams JF, Newsholme EA (1989) Pyruvate metabolism by lymphocytes: evidence for an additional ketogenic tissue. Biochem Int 19:755-767

Dahlgren C, Karlsson A (1999) Respiratory burst in human neutrophils. J Immunol Methods 232:3-14

Das UN (2006a) Is pyruvate an endogenous anti-inflammatory molecule? Nutrition 22:965-972

Das UN (2006b) Pyruvate is an endogenous anti-inflammatory and anti-oxidant molecule. Med Sci Monit 12:79-84

Dave SH, Tilstra JS, Matsuoka K et al (2009) Ethyl pyruvate decreases HMGB1 release and ameliorates murine colitis. J Leukoc Biol 86:633-643

Deng ZH, Ti DD, Xue H et al (2009) Effects of ethyl pyruvate on injuries of sepsis in mice. Zhongguo Wei Zhong Bing Ji Jiu Yi Xue 21:460-462

Di PR, Mazzon E, Genovese T et al (2009) Ethyl pyruvate reduces the development of zymosan-induced generalized inflammation in mice. Crit Care Med 37:270-282

Dooley DC, Simpson JF, Meryman HT (1982) Isolation of large numbers of fully viable human neutrophils: a preparative technique using percoll density gradient centrifugation. Exp Hematol 10:591-599

Edlund GL, Halestrap AP (1988) The kinetics of transport of lactate and pyruvate into rat hepatocytes. Evidence for the presence of a specific carrier similar to that in erythrocytes. Biochem $\mathrm{J}$ 249:117-126

Eggleton P, Gargan R, Fisher D (1989) Rapid method for the isolation of neutrophils in high yield without the use of dextran or density gradient polymers. J Immunol Methods 121:105-113 
Engel JM, Mühling J, Kwapisz M, Heidt M (2009a) Glutamine administration in patients undergoing cardiac surgery and the influence on blood glutathione levels. Acta Anaesthesiol Scand 53:1317-1323

Engel JM, Pitz S, Mühling J, Menges T, Martens F, Kwapisz M, Hempelmann G (2009b) Role of glutamine administration on T-cell derived inflammatory response after cardiopulmonary bypass. Clin Nutr 28:15-20

Fauth U, Heinrichs W, Puente-Gonzalez I et al (1990) Maximale Umsatzraten an Enzymen der Glykolyse und des Zitratzyklus von separierten Granulozyten in der postoperativen Phase. Maximal turnover rates of glycolysis enzymes and of the citrate cycle of separated granulocytes in the postoperative period. Infusionstherapie 17:178-183

Fauth U, Schlechtriemen T, Heinrichs W et al (1993) The measurement of enzyme activities in the resting human polymorphonuclear leukocyte-critical estimate of a method. Eur J Clin Chem Clin Biochem 31:5-16

Fink MP (2004) Ethyl pyruvate: a novel treatment for sepsis and shock. Minerva Anestesiol 70:365-371

Fink MP (2007a) Ethyl pyruvate: a novel anti-inflammatory agent. J Intern Med 261:349-362

Fink MP (2007b) Ethyl pyruvate: a novel treatment for sepsis. Curr Drug Targets 8:515-518

Fink MP (2008) Ethyl pyruvate. Curr Opin Anaesthesiol 21:160-167

Frei J, Aellig A, Nessi P (1975) Enzyme system and coenzymes involved in the energy metabolism of leukocytes. Function and metabolism of polymorphonuclear neutrophils. Ann Biol Clin (Paris) 33:459-464

Fuchs M, Gerlach J, Unger J et al (1994) Alpha-keto acid metabolism by hepatocytes cultured in a hybrid liver support bioreactor. Int $\mathrm{J}$ Artif Organs 17:554-558

Gabbianelli R, Cifani C, Massi M et al (2007) Oxidative damage in rat erythrocyte membranes following ethanol intake: effect of ethyl pyruvate. Chem Biol Interact 169:122-131

Gardner DK, Leese HJ (1988) The role of glucose and pyruvate transport in regulating nutrient utilization by preimplantation mouse embryos. Development 104:423-429

Genovese T, Esposito E, Mazzon E et al (2009) Beneficial effects of ethyl pyruvate in a mouse model of spinal cord injury. Shock 32:217-227

Halestrap AP (1978) Pyruvate and ketone-body transport across the mitochondrial membrane. Exchange properties, $\mathrm{pH}-$ dependenceand mechanism of the carrier. Biochem J 172:377387

Han Y, Englert JA, Yang R et al (2005) Ethyl pyruvate inhibits nuclear factor-kappaB-dependent signaling by directly targeting p65. J Pharmacol Exp Ther 312:1097-1105

Haslett C, Guthrie LA, Kopaniak MM, Johnston RB Jr, Henson PM (1985) Modulation of multiple neutrophil functions by preparative methods or trace concentrations of bacterial lipopolysaccharide. Am J Pathol 119:101-110

Hollenbach M, Hintersdorf A, Huse K et al (2008) Ethyl pyruvate and ethyl lactate down-regulate the production of pro-inflammatory cytokines and modulate expression of immune receptors. Biochem Pharmacol 76:631-644

Homem de Bittencourt PI, Jr PeresCM et al (1993) Pyruvate is a lipid precursor for rat lymphocytes in culture: evidence for a lipid exporting capacity. Biochem Mol Biol Int 30:631-641

Huang LF, Yao YM, Zhang LT et al (2009) The effect of highmobility group box 1 protein on activity of regulatory $\mathrm{T}$ cells after thermal injury in rats. Shock 31:322-329

Hume DA, Vijayakumar EK, Schweinberger F et al (1978) The role of calcium ions in the regulation of rat thymocyte pyruvate oxidation by mitogens. Biochem J 174:711-716
Hyslop PA, Oades ZG, Jesaitis AJ et al (1984) Evidence for N-formyl chemotactic peptide-stimulated GTPase activity in human neutrophil homogenates. FEBS Lett 166:165-169

Ing TS, Zhou XJ, Yu AW et al (1997) Effects of pyruvate-based or lactate-based peritoneal dialysis solutions on neutrophil intracellular pH. Int J Artif Organs 20:255-260

Johansson AS, Johansson-Haque K, Okret S et al (2008) Ethyl pyruvate modulates acute inflammatory reactions in human endothelial cells in relation to the NF-kappaB pathway. Br J Pharmacol 154:1318-1326

Jolkver E, Emer D, Ballan S et al (2009) Identification and characterization of a bacterial transport system for the uptake of pyruvate, propionate, and acetate in Corynebacterium glutamicum. J Bacteriol 191:940-948

Kang YH, Park SH, Lee YJ et al (2002) Antioxidant alpha-ketocarboxylate pyruvate protects low-density lipoprotein and atherogenic macrophages. Free Radic Res 36:905-914

Kielducka A, Paradies G, Papa S (1981) A comparative study of the transport of pyruvate in liver mitochondria from normal and diabetic rats. J Bioenerg Biomembr 13:123-132

Klein A, Chan AW, Caplan BU et al (1990) NADP+ reduction by human lymphocytes. Clin Exp Immunol 82:170-173

Knox WE, Stumpf PK, Green DE, Auerbach VH (1948) The inhibition of sulfhydryl enzymes as the basis of the bactericidal action of chlorine. J Bacteriol 55:451-458

Kobayashi T, Tsunawaki S, Seguchi H (2001) Evaluation of the process for superoxide production by NADPH oxidase in human neutrophils: evidence for cytoplasmic origin of superoxide. Redox Rep 6:27-36

Kozlova NM, Slobozhanina EI, Chernitskii EA et al (1983) Pyruvate and glucose transport through the erythrocyte membranes and the role of spectrin in these processes. Biofizika 28:826-829

Krebs HA (1940) The citric acid cycle and the Szent-Gyorgyi cycle in pigeon breast muscle. Biochem J 34:775-779

Krebs HA, Salvin E, Johnson WA (1938) The formation of citric and alpha-ketoglutaric acids in the mammalian body. Biochem $\mathbf{J}$ 32:113-117

Krumholz W, Demel C, Jung S, Meuthen G, Hempelmann G (1993) The influence of intravenous anaesthetics on polymorphonuclear leukocyte function. Can J Anaesth 40:770-774

Krumholz W, Demel C, Jung S, Meuthen G, Knecht J, Hempelmann G (1995) The effects of thiopentone, etomidate, ketamine and midazolam on several bactericidal functions of polymorphonuclear leucocytes in vitro. Eur J Anaesthesiol 12:141-146

Lamers JM, Hulsmann WC (1975) Inhibition of pyruvate transport by fatty acids in isolated cells from rat small intestine. Biochim Biophys Acta 394:31-45

Lee J, Kwon W, Jo Y et al (2008) Protective effects of ethyl pyruvate treatment on paraquat-intoxicated rats. Hum Exp Toxicol 27:49-54

Liang X, Chavez AR, Schapiro NE et al (2009) Ethyl pyruvate administration inhibits hepatic tumor growth. J Leukoc Biol 86:599-607

Mackenzie I, Lever A (2007) Management of sepsis. BMJ 335:929-932

Mahiout A, Matata BM, Brunkhorst R (1997) Effect of glucose and pyruvate in acidic and non-acidic peritoneal dialysis fluids on leukocytes cell functions. Kidney Int 51:860-867

Matés JM, Segura JA, Alonso FJ et al (2008) Intracellular redox status and oxidative stress: implications for cell proliferation, apoptosis, and carcinogenesis. Arch Toxicol 82:273-299

Matsumoto T, van der AP, Watanabe Y et al (1991) Neutrophil function in hyperosmotic $\mathrm{NaCl}$ is preserved by phosphoenol pyruvate. Urol Res 19:223-227

McCarthy, Bernhagen J, Liu YC, Perry JD (1990) A rapid preparation technique for leucocytes. J Microsc 158: 63-72 
Merezhinskaya N, Fishbein WN (2009) Monocarboxylate transporters: past, present, and future. Histol Histopathol 24:243-264

Miwa H, Fujii J, Kanno H et al (2000) Pyruvate secreted by human lymphoid cell lines protects cells from hydrogen peroxide mediated cell death. Free Radic Res 33:45-56

Mühling J, Fuchs M, Dehne MG et al (1999) Quantitative determination of free intracellular amino acids in single human polymorphonuclear leucocytes. Recent developments in sample preparation and high-performance liquid chromatography. J Chromatogr B Biomed Sci Appl 728:157-166

Mühling J, Dehne MG, Fuchs M et al (2001) Conscientious metabolic monitoring on a patient with hyperornithinemia-hyperammonemia-homocitrullinuria $(\mathrm{HHH})$ syndrome undergoing anaesthesia. Amino Acids 21:303-318

Mühling J, Fuchs M, Sablotzki A et al (2002) Effects of arginine, L-alanyl-L-glutamine or taurine on neutrophil (PMN) free amino acid profiles and immune functions in vitro. Amino Acids 22:39-53

Mühling J, Fuchs M, Campos ME et al (2003) Quantitative determination of free intracellular alpha-keto acids in neutrophils. J Chromatogr B Analyt Technol Biomed Life Sci 789:383-392

Mühling J, Fuchs M, Campos M et al (2004) Effects of ornithine on neutrophil (PMN) free amino acid and alpha-keto acid profiles and immune functions in vitro. Amino Acids 27:313-319

Mühling J, Nickolaus KA, Halabi M et al (2005) Alterations in neutrophil (PMN) free intracellular alpha-keto acid profiles and immune functions induced by L-alanyl-L-glutamine, arginine or taurine. Amino Acids

Mühling J, Engel J, Halabi M et al (2006) Nitric oxide and polyamine pathway-dependent modulation of neutrophil free amino- and alpha-keto acid profiles or host defense capability. Amino Acids 31:11-26

Mühling J, Burchert D, Langefeld TW et al (2007) Pathways involved in alanyl-glutamine-induced changes in neutrophil amino- and alpha-keto acid homeostasis or immunocompetence. Amino Acids 33:511-524

Mühling J, Tussing F, Nickolaus KA, Matejec R, Henrich M, Harbach H, Wolff M, Weismuller K, Engel J, Welters ID, Langefeld TW, Fuchs M, Weigand MA, Heidt MC (2010) Effects of alphaketoglutarate on neutrophil intracellular amino and alpha-keto acid profiles and ROS production. Amino Acids 38:167-177

Newsholme P, Gordon S, Newsholme EA (1987) Rates of utilization and fates of glucose, glutamine, pyruvate, fatty acids and ketone bodies by mouse macrophages. Biochem J 242:631-636

Paul JL, Roch-Arveiller M, Giroud JP et al (1987) Effects of storage on the pyruvate-lactate system and random migration of human granulocytes. Vox Sang 52:24-26

Poole RC, Halestrap AP, Price SJ et al (1989) The kinetics of transport of lactate and pyruvate into isolated cardiac myocytes from guinea pig. Kinetic evidence for the presence of a carrier distinct from that in erythrocytes and hepatocytes. Biochem $\mathbf{J}$ 264:409-418

Ramakrishnan N, Chen R, McClain DE et al (1998) Pyruvate prevents hydrogen peroxide-induced apoptosis. Free Radic Res 29:283-295

Rebecchi IM, Ferreira-Novo N, Julian Y, Campa A (2000) Oxidative metabolism and release of myeloperoxidase from polymorphonuclear leukocytes obtained from blood sedimentation in a Ficoll-Hypaque gradient. Cell Biochem Funct 18:127-132

Riedel E, Hampl H, Nündel M, Busche D, Fuchs H (1992) Severity of anaemia influences pattern of amino acids and alpha-keto acids in haemodialysis patients. Contrib Nephrol 98:98-104

Selvaraj RJ, Sbarra AJ (1966) Phagocytosis inhibition and reversal. II. Possible role of pyruvate as an alternative source of energy for particle uptake by guinea-pig leukocytes. Biochim Biophys Acta 127:159-171
Serrano MA, Curi R (1989) Rates of pyruvate utilization and lactate formation by lymphocytes from young and aged rats. Braz J Med Biol Res 22:555-559

Stjernholm RL, Dimitrov NV, Pijanowski LJ (1969) Carbohydrate metabolism in leukocytes. IX. Citric acid cycle activity in human neutrophils. J Reticuloendothel Soc 6:194-201

Su F, Wang Z, Cai Y et al (2007) Beneficial effects of ethyl pyruvate in septic shock from peritonitis. Arch Surg 142:166-171

Su J, Li X, Cui X et al (2008) Ethyl pyruvate decreased early nuclear factor-kappaB levels but worsened survival in lipopolysaccharide-challenged mice. Crit Care Med 36:1059-1067

Taylor MD, Grand TJ, Cohen JE et al (2005) Ethyl pyruvate enhances ATP levels, reduces oxidative stress and preserves cardiac function in a rat model of off-pump coronary bypass. Heart Lung Circ 14:25-31

Tsung A, Kaizu T, Nakao A et al (2005) Ethyl pyruvate ameliorates liver ischemia-reperfusion injury by decreasing hepatic necrosis and apoptosis. Transplantation 79:196-204

Vaartjes WJ, Geelen MJ, van den Bergh SG (1979) Accumulation of pyruvate by isolated rat liver mitochondria. Biochim Biophys Acta 548:38-47

Van Zoelen MA, Bakhtiari K, Dessing MC et al (2006) Ethyl pyruvate exerts combined anti-inflammatory and anticoagulant effects on human monocytic cells. Thromb Haemost 96:789-793

Varma SD, Hegde KR, Kovtun S (2006) Oxidative damage to lens in culture: reversibility by pyruvate and ethyl pyruvate. Ophthalmologica 220:52-57

Venizelos N, Hagenfeldt L (1985) Pyruvate and acetate oxidation by leukocytes in vitro. Activation of the pyruvate dehydrogenase complex by uncoupling of oxidative phosphorylation. Scand J Clin Lab Invest 45:335-340

Wang Q, Ding Q, Zhou Y et al (2009) Ethyl pyruvate attenuates spinal cord ischemic injury with a wide therapeutic window through inhibiting high-mobility group box 1 release in rabbits. Anesthesiology 110:1279-1286

Welters ID (2002) Effekte von Morphin, Fentanyl und Ketamin auf leukozytäre Funktion, Transkriptionsfaktoren und Interleukin-8Synthese. Habilitationsschrift zur Erlangung der Venia legendi des Fachbereichs Humanmedizin der Justus, Liebig-Universität Gießen

Wiemer EA, Michels PA, Opperdoes FR (1995) The inhibition of pyruvate transport across the plasma membrane of the bloodstream form of Trypanosoma brucei and its metabolic implications. Biochem J 312(Pt 2):479-484

Willems HL, de Kort TF, Trijbels FJ et al (1978) Determination of pyruvate oxidation rate and citric acid cycle activity in intact human leukocytes and fibroblasts. Clin Chem 24:200-203

Witko-Sarsat V, Rieu P, Descamps-Latscha B et al (2000) Neutrophils: molecules, functions and pathophysiological aspects. Lab Invest 80:617-653

Woodman RC, Curnutte JT, Babior BM (1988) Evidence that de novo protein synthesis participates in a time-dependent augmentation of the chemotactic peptide-induced respiratory burst in neutrophils. Effects of recombinant human colony stimulating factors and dihydrocytochalasin B. Free Radic Biol Med $5: 355-361$

Wu YT, Wu ZL, Jiang XF et al (2003) Pyruvate preserves neutrophilic superoxide production in acidic, high glucoseenriched peritoneal dialysis solutions. Artif Organs 27:276-281

Wu YT, Wu ZL, Jiang XF et al (2005) Pyruvate improves neutrophilic nitric oxide generation in peritoneal dialysis solutions. Artif Organs 29:976-980

Yang R, Shaufl AL, Killeen ME et al (2009) Ethyl pyruvate ameliorates liver injury secondary to severe acute pancreatitis. J Surg Res 153:302-309 
Zhang Y, Li M, Meng M et al (2009) Effect of ethyl pyruvate on physical and immunological barriers of the small intestine in a rat model of sepsis. J Trauma 66:1355-1364

Zhao J, Juettner B, Scheinichen D et al (2003) Respiratory burst activity of polymorphonuclear cells is dependent on the cell preparation technique. Acta Anaesthesiol Scand 47:702-770
Zhou FQ, Yu AW (1998) Pyruvate-based peritoneal dialysate preserves neutrophilic oxygen consumption. Zhongguo Yao Li Xue Bao 19:207-210

Zingarelli B (2004) Ethyl pyruvate: a simple solution? Crit Care Med $32: 1603-1604$ 